Journal of Patient-Centered

Volume 4

Issue 4 -- Health Disparities and Inequities: Part

Article 9 I

$11-6-2017$

\title{
Assessment of Chronic Disease to Determine Appropriateness of Implantable Cardioverter-Defibrillator Therapy
}

\author{
Bilal M. Omery \\ Maharaj Singh \\ Randy S. Turkel \\ Robyn Shearer \\ Arshad Jahangir \\ M. Eyman Mortada \\ Jasbir S. Sra \\ Indrajit Choudhuri
}

Follow this and additional works at: https://aah.org/jpcrr

Part of the Cardiology Commons, Cardiovascular Diseases Commons, Cardiovascular System Commons, and the Surgical Procedures, Operative Commons

\section{Recommended Citation}

Omery BM, Singh M, Turkel RS, Shearer R, Jahangir A, Mortada ME, Sra JS, Choudhuri I. Assessment of chronic disease to determine appropriateness of implantable cardioverter-defibrillator therapy. J Patient Cent Res Rev. 2017;4:256.

Published quarterly by Midwest-based health system Advocate Aurora Health and indexed in PubMed Central, the Journal of Patient-Centered Research and Reviews (JPCRR) is an open access, peer-reviewed medical journal focused on disseminating scholarly works devoted to improving patient-centered care practices, health outcomes, and the patient experience. 


\section{Conference Proceedings: Aurora Scientific Day 2017}

The following abstracts were presented at the 43rd Annual Aurora Scientific Day research symposium, held May 24, 2017, in Milwaukee, Wisconsin. Aurora Scientific Day hosts a forum for original research conducted by faculty, fellows, residents, and other allied health professionals affiliated with Aurora Health Care, an integrated health system with hospital and clinic locations in eastern Wisconsin and northern Illinois.

FIRST PLACE POSTER

Assessment of Chronic Disease to Determine
Appropriateness of Implantable Cardioverter-
Defibrillator Therapy

Bilal M. Omery, Maharaj Singh, Randy S. Turkel, Robyn Shearer, Arshad Jahangir, M. Eyman Mortada, Jasbir S. Sra, Indrajit Choudhuri

Aurora Cardiovascular Services; Sheikh Khalifa bin Hamad Al Thani Center for Integrative Research on Cardiovascular Aging, Aurora Research Institute

Background: Implantable cardioverter-defibrillator (ICD) therapy is considered appropriate when a patient is felt to have a reasonable expectation of 1-year survival. Chronic diseases have been estimated to be associated with greater than $10 \%$ annual mortality and may reduce benefits of ICD therapy. Frailty has been estimated to be associated with greater than $20 \%$ annual mortality and has been suggested to contraindicate ICD therapy.

Purpose: Determine a risk score that may identify patients in whom ICD implantation may not be appropriate.

Methods: Patients who received an ICD for primary and secondary prevention from 2008 through 2013 at the Aurora Health Care network were studied retrospectively. Using Cox regression, a scoring system based on hazard ratios was devised to reflect risk associated with comorbidities. Survival was evaluated by KaplanMeier estimates.

Results: The study cohort includes 1,558 patients (mean age: 61.3 years; 495 female). Comorbidities associated with mortality included in the risk score were need for hemodialysis, myocardial infarct within 3 months prior to ICD implantation, sustained monomorphic ventricular tachycardia, New York Heart Association functional class III, age greater than 70 years, intraventricular conduction delay, diabetes mellitus, and chronic lung disease. A risk score of greater than or equal to 6 was associated with $10 \%$ mortality at 1 year and more than $20 \%$ mortality by 2 years.

Conclusion: Chronic comorbidities have a cumulative effect on mortality. Using our scoring system, patients with a risk score of 6 or greater have at least $10 \%$ mortality at 1 year and more than $20 \%$ mortality by 2 years.

\section{SELECT ABSTRACTS}

Sensitivity of Current Methods for Diagnosing and Documenting Metabolic Syndrome Within a Large Community-Based Health Care System

Tiffany A. Mullen, Danielle M. Greer, Jennifer T. Fink, Renee E. Walker

Department of Integrative Medicine, Aurora Sinai Medical Center; Center for Urban Population Group; Aurora University of Wisconsin Medical Group; Department of Health Informatics and Administration and Zilber School of Public Health, University of Wisconsin-Milwaukee

Background: Metabolic syndrome (MetS) is a constellation of metabolic conditions, including abdominal obesity, high blood pressure, high triglyceride level, low high-density-lipoprotein level and high fasting blood glucose level, that increase the risk of developing chronic health conditions. Various combinations of diagnostic criteria have been proposed, including those by the National Cholesterol Education Program Adult Treatment Panel III (ATP III), World Health Organization (WHO) and International Diabetes Foundation (IDF), among others. However, inconsistent use of diagnostic criteria and inadequate scientific evidence supporting use of specific criteria are current problems in health care.

Purpose: Quantify the prevalence of MetS diagnosis within the Aurora Health Care patient population and determine the sensitivity (ie, accuracy) achieved in documenting MetS within Aurora, recognizing ATP III, WHO and IDF definitions of MetS as diagnostic gold standards.

Methods: We conducted a retrospective review of all patients encountered within Aurora from January 1, 2012, to December 31, 2015. Patients were examined to determine the occurrence and associated dates of MetS diagnosis and all indications of satisfied MetS diagnostic criteria. Indications of obesity, hyperglycemia, hypertriglyceridemia, hypoalphalipoproteinemia and hypertension, as variably defined in ATP III, WHO and IDF guidelines, included relevant diagnoses, abnormal clinical and laboratory test results and use of medications. Sociodemographic data also were collected.

Results: In total, 1,369,620 unique patients visited Aurora during the study period, with $28 \%$ of patients aged $\geq 60$ years and most identifying as non-Hispanic white $(76.8 \%)$ or black $(9.93 \%)$ race. Only 4,978 patients $(0.36 \%)$ received a clinical diagnosis of MetS despite evidence of satisfied ATP III and WHO criteria in $12.0 \%$ and $16.7 \%$ of patients, respectively. Satisfaction of IDF criteria occurred in only $0.16 \%$ of patients. Except for hyperglycemia, individual diagnostic criteria also showed lower-than-expected rates of clinical diagnosis. For example, obesity was diagnosed in $7.86 \%$ of patients but suggested in $39.3 \%$ of patients with body mass index $\geq 30 \mathrm{~kg} / \mathrm{m}^{2}$. The true positive rate (ie, percentage of patients with satisfied criteria who also were clinically diagnosed) was lowest in older, male, black or Hispanic patients. 